\title{
Unveiling cultures in emergency response communication networks on social media: following the 2016 Louisiana floods
}

\author{
Jungwon Yeo ${ }^{1}$ Claire Connolly Knox ${ }^{2}$ Kyujin Jung ${ }^{3}$
}

Published online: 13 October 2017

(C) Springer Science+Business Media B.V. 2017

\begin{abstract}
While culture in emergency management has gained attention from the field of risk communication, few have systemically dealt with the nuances of general culture involved in the formation and differentiation of risk communication. To fill this gap, this research aims to first examine cultural nuances from the 2016 Louisiana flood response by primarily focusing on communications embedded in social media. The results from social network analysis and content analysis highlight that the flood response communication had strong cultural characteristics, highlighting the notion that of the cultures in Louisianafaith-based, local authority, and nonprofits-were the prominent cultural responders in the flood response communication. In particular, cultural similarity in both intra/inter group response communication was observed, with each communication group comprising actors who shared a common cultural background and spoke similar keywords.
\end{abstract}

Keywords Louisiana floods $\cdot$ Culture $\cdot$ Response communication · Social media - Network analysis

\footnotetext{
Kyujin Jung

Kjung1@korea.ac.kr

Jungwon Yeo

Jungwon.Yeo@ucf.edu

Claire Connolly Knox

claire.knox@ucf.edu
}

1 School of Public Administration, College of Health and Public Affairs, University of Central Florida, BYC101B, 12805 Pegasus Drive, Orlando, FL 32816, USA

2 School of Public Administration, College of Health and Public Affairs, University of Central Florida, Rm235, 12805 Pegasus Drive, Orlando, FL 32816, USA

3 Social Disaster \& Safety Management Center, College of Liberal Arts, Korea University, Rm 203B, Inchon-ro 108, Seongbuk-gu, Seoul 02841, Korea 


\section{Introduction}

Culture is an important factor to understand communication and coordination across diverse people, groups, and organizations. As a set of individuals as well as a sub-set of social influence (Axelrod 1997), cultures shapes communication patters among different entities (Centola et al. 2007; Tinsley and Brett 2001). Cultures influence individual' choices of communication partners, thus drive the formation and differentiation of communication groups over time (McPherson et al. 2001). For example, people tend to interact with others having similar cultural background more frequently than with those who have different cultures (Centola et al. 2007).

The cultural impact is much stronger in emergency response communication (Weare et al. 2014; Mileti 1999). Devastated people may feel more comfortable interacting with those who already share similar values, beliefs, and behaviors than with those who do not (Xiao and Tsui 2007; Knoke 1990). In addition, given the urgency and complexity of the situation, thoughts and actions can be easily justified and shared across actors standing on a common ground (Centola et al. 2007).

In contrast to the importance, cultures have been under-explored in emergency response communication studies. Fewer studies have exclusively explored the nuances of cultures in general, or the formation and differentiation of risk communication based on understanding of the cultural nuances. In addition, compared to the large volume of communication studies in disaster management, lesser volume of studies has explored the cultural tendencies embedded in communication structures in the context. Previous studies tend to focus on minorities' culture and cultural competency and awareness of majority emergency managers (Bergeron 2014; Renzaho and Oldroyd 2014; Tovar et al. 2014; Mileti 1999; Cross 1989). Therefore, operational definitions of cultures have been limited to certain ethnic, lingual, or racial groups. If not, cultures have been treated as control or contextual variables which are not the main antecedents of emergency response communication, but just something else to have in mind.

To address this gap in the literature, we explored cultural nuances of the 2016 Southern Louisiana flood response communications, posing three research questions: (1) how was the flood response communication organized? (2) were there emerging cultural indicators of the flood response communication? and (3) what were the cultural nuances of 2016 Louisiana flood response communication?

To answer the questions, we utilized an innovative method to examine cultural tendencies embedded in risk communication structure. In particular, we extracted communication log data from Twitter (an online news and communication services), and conducted social network analysis and content analysis.

The following sections review the literature, and provide in-depth information about Louisiana cultures. Next, the context of the case study, 2016 Louisiana Flood, is introduced. Then, after reviewing the methods, the results are presented. Lastly, the study concludes with a brief summary of results, policy implications, limitations, and future research recommendations. 


\section{Literature review}

\subsection{Cultures and emergency response communication}

Culture is "the collective programming of the mind that distinguishes one group or category of people from another" (Hofstede 1993, p. 89). In practice, culture can be understood as "shared motives, experiences, values, beliefs, identities, and interpretations or meanings of significant events that result from common experiences of members of collectives and are transmitted across age generations" (House et al. 2004, p. 15).

Cultural diversities are prevalent in crises and disasters (Sylves 2008). Any disaster, regardless of size, cause, and location, can affect multiple individuals and communities, and highlight their culture in the emergency management setting. For example, different languages or terms may be spoken on site between responders and community members. Moreover, diverse organizational, ethnic, or religious customs or experiences can be present, such as different ages, marital statuses, experiences, and abilities among the people affected by emergencies and crises (Comfort et al. 2013).

Therefore, culturally appropriate and adaptive communication is necessary for the quality and effectiveness of emergency management (Canton 2015; Bergeron 2014; HHS OMH 2013; Reynolds and Seeger 2005). In contrast, culturally ignorant communication may cause undesirable results in emergency management (Bergeron 2014; Neal and Phillips 1995). Cultural misunderstanding may induce conflicts and impede coordination among diverse stakeholders and delay the disaster response process or even aggravate the crises situation.

Scholars have established that culture is an important parameter in crisis communication (e.g., Falkheimer and Heide 2006; Lee 2004; Lui et al. 2015). Cultural dimensions commonly studied at the national level are trust, individualism-collectivism, masculinityfemininity, and power distance (Falkheimer and Heide 2006; Hofstede 1993; Lui et al. 2015). While researchers are studying culture in crisis communication, it is primarily organizational culture or national level culture. For example, Zhu et al. (2017) studied crisis communication response from two multinational corporations in China. Results conclude the need to contextualize the crisis communication with culture is essential for the stakeholder's perception of specific response strategies and role of influential social media users. Analyzing a local community's culture in social mediated crisis communication remains understudied.

\subsection{Communication and social media platform in emergency management}

Emergency management scholars have focused on communication efforts across sectors and levels of government (Yeo and Comfort 2017; Comfort et al. 2013; Cohen et al. 2002; Comfort et al. 2004, 2012; Hu et al. 2014; Kapucu 2006a, b; Waugh and Streib 2006; Kim et al. 2015). Similarly, Federal policies have directly addressed communication efforts amongst stakeholders, including the Post-Katrina Emergency Management Act of 2006, National Response Framework, Presidential Preparedness Directive 8, and the National Disaster Recovery Framework (Harrald 2012; Hu et al. 2014). Best practices state emergency managers should incorporate multiple methods of communication to assist residents, visitors, and other stakeholders to prepare for, respond to, recover from, and mitigate for an emergency or disaster (Tinker and Vaughan 2010). 
There remains an increased need from the public to incorporate and monitor social media platforms during disasters, especially the ability of officials to facilitate collaborative interactions in multiple aspects of disaster governance (Knox 2016; Lui et al. 2015; Palttala et al. 2012). With the increased use of social media platforms, emergency management and crisis communication research has evolved to investigate and analyze the effectiveness of these tools. Researchers have studied the use of social media among minorities and vulnerable populations (Pennington-Gray et al. 2013), by public information officers (Hughes and Palen 2012), to capture climate change denial discourses before, during, and after Superstorm Sandy (Jacques and Knox 2016), regarding knowledge management during the 2010 Haitian earthquake (Yates and Paquette 2011), critical crisis communication during the 2013 Westgate Mall terror attack in Kenya (Simon et al. 2014), and social media crisis communication during the 2013 Boston Marathon Bombings (Lui et al. 2015).

\section{Case}

\subsection{Louisiana's unique and strong cultures}

There are a variety of cultures present in southern Louisiana, including ethnic (e.g., Acadians, Creole, Native Americans, Vietnamese, Cambodians, Croatians, and Irish), religious (primarily Catholic and Christian), and distrust of authority.

The churches are not simply a symbol of faith, but an integral element of a community's social network, identity, and resiliency. Researchers highlight the important role of churchbased social capital and networking during disasters with a case study of a local Catholic church within a Versailles Vietnamese Community after Hurricane Katrina. Specifically, Mary Queen of Vietnam Church mediated critical response and recovery efforts with local, state, national, and international agencies and organizations. Therefore, when compared to other neighboring communities, these residents returned sooner and in greater numbers (Airriess et al. 2008; Leong et al. 2007). While the Catholic Church was the primary religion in many southern Louisiana communities, especially in Lafayette Parish, the past decade has seen a shift from Roman Catholic to Christian. In a 2014 survey, the Pew Research Center reported Louisiana residents are 84\% Christian, which includes 27\% Evangelical Protestant, 26\% Catholic, 22\% Historically Black Protestant, and 8\% Mainline Protestant.

As discussed in Jurkiewicz (2007), residents of southern Louisiana have a long history of distrust of authority figures, which often is the source of cultural jokes about Boudreaux and Thibodeaux. Yet, the lack of response from local, state, and federal government officials during and after Hurricanes Katrina and Rita reinforced this distrust. Researchers have written about this unethical behavior, especially from New Orleans Mayor Ray Nagin, law enforcement officers, Louisiana Governor Kathleen Babineaux Blanco, FEMA Director Michael Brown, and President George W. Bush (Ancelet et al. 2013; Eikenberry et al. 2007; Jurkiewicz 2007, 2009). The level of distrust at the state and local level is shifting. Currently, Governor John Bel Edwards (D) is serving his first term with a $63 \%$ approval rating; however, the outgoing republican governor, Governor Jindal, had one of the lowest approval ratings in the state's history (below 30\%) (O'Donoghue 2016). While the public trust in the federal government is at an all-time low at $19 \%$, public trust of local 
government officials has maintained at $63 \%$ and state government officials at $57 \%$ (Pew Research Center 2013, 2015).

Humanitarian assistance, especially between neighbors and communities, is another strong element in Louisiana's culture. As witnessed during Hurricanes Katrina and Rita, local, national, and international nonprofit organizations had a positive impact to the response and recovery efforts (Eikenberry et al. 2007). As noted in the literature, collaborations between the public, nonprofit, and private sectors contribute to a community's resilience before, during, and after an emergency or disaster (Kapucu 2006b).

Louisiana possesses a unique and clearly defined culture that exerts a strong and dynamic influence on behavior and cognitions (Rosenthal and Masarech 2003). This region is known for its close knit communities with high levels of social capital, which stems from the churches, culture (i.e., festivals, traditions, music, food, etc.), and surviving disasters (Simms 2016; Jurkiewicz 2007). While disasters have impacted southern Louisiana for centuries, the more recent history has strained established social capital and networks, which makes this particular case study ripe for analysis.

\subsection{Case: southern Louisiana flood 2016}

The unnamed storm was a rare tropical-mid-latitude interaction in which a slow-moving, tropical, low-pressure system combined with an upper trough and accompanying surface cyclone. Multiple forecasting models (i.e., Global Forecast System and Climate Forecast System) were unable to predict this extreme precipitation event before August 9, 2016. Therefore, related warning category limits were not met and forewarnings were not issued. Emergency managers were limited in their decision-making abilities and provided warnings after the precipitation began on August 11 and the rivers started cresting. The heaviest precipitation occurred on August 12 and 13, and the intense precipitation was approximately three times more than during Hurricane Katrina (Wang et al. 2016).

Within the first few days of the storm, more than 30,000 people evacuated; some of whom were victims of Hurricane Katrina and Rita in 2005 (Wang et al. 2016). Individuals and families were rescued by neighbors, local government officials and emergency workers, the National Guard, and the Coast Guard (Domonoske 2016; Gunn and Cook 2016).

Governor Edwards declared a state of emergency on August 12, 2016 and President Obama approved a Disaster Declaration (DR-4277) for 22 parishes 2 days later. The Federal Emergency Management Agency estimates that approximately $\$ 170$ Million provided for Housing Assistance, \$2.9 Million for Public Assistance with nearly 106,000 individuals applying for aid, and \$11 Million paid to National Flood Insurance Program policyholders. It is the costliest disaster since Superstorm Sandy.

Estimates place damage from this flood between $\$ 10$ and $\$ 15$ Billion with many uninsured residents. The flood damaged nearly 110,000 homes and 100,000 vehicles. One of the issues is that local land use plans used outdated flood maps from 1996; therefore, residents were unaware their subdivisions were built in a flood zone and that they needed flood insurance. In fact, approximately $80 \%$ of those homes did not have flood insurance (Chiglinsky 2016). Not only do the flood maps need to be updated, they also need to account for climate change. FEMA officials update the flood insurance maps every 5 years, which may not be accounting for the effects of climate change (Joyce 2016). Specific to this case study, model simulations estimate that between 10 and $20 \%$ of the precipitation in the Louisiana Flood could be attributed to climate change (van der Wiel, et al. 2016; Wang et al. 2016). Researchers have concluded that the effects of climate change increase the risk 
of losing diverse cultures and language especially in coastal communities (Adger et al. 2011).

The flooded parishes have seen an increase in population, especially after a portion of individuals who evacuated for Hurricane Katrina and Rita took up residency in the Baton Rouge and Lafayette areas. Ten years later, records show that Baton Rouge nearly doubled its population after the 2005 storms - adding and maintaining nearly 90,000 new residents Mitchell Mitchell (2015). With this increased population came urban sprawl into surrounding communities. Southern Lafayette Parish has dramatically changed in the past 10 years with Youngsville-one of the hardest hit cities in the 2016 flood-being the fastest growing city. Since 1990, the population has increased $143 \%$ with a population nearing 10,000 (Decker 2014).

\section{Methods}

\subsection{Data}

In this study, we utilized Twitter data streams. It is advantageous to use Twitter data streams in investigating communication since the system is designed to support millions of users' information sharing with open public about ongoing event at any moment around the world (Weng et al. 2013). Twitter stream data is distinctive from other web-based engines. Traditional web search engines are useful to identify user's intention, desire, wants, or needs. In contrast, Twitter data streams identify users' actions and thoughts about current events. In addition, with the technological support of the social media platform, the data stream can capture direct interactions among the users, and a user's information sharing through denotation of other users and reposting other's initial postings (Bifet et al. 2011). Therefore, the Twitter data- Twitter contents and interaction behaviors among the users-are useful to examining patterns of human communication behaviors (Weng et al. 2013). This study investigated Twitter data streams from September 9-16, 2016, which is 2 weeks after the last date of the flood inundation, August 25, 2016. The time frame is important to observe the disaster response communication. During the time frame, response activities were still underway while the recovery operations were initiated. In addition, during the time, information was shared across stakeholders to make important decisions about the longer-term response and attempting to return all system back to their normal state. Therefore, the observation period allowed evaluating specific communication behaviors and actions of stakeholders emerged during the longer-term response phase.

This research utilized NodeXL for extracting data streams of communication and cultures embedded in the communication from Twitter. NodeXL is a network analysis software program that supports automated data process from data extraction to modeling, analyzing, and visualizing network from the extracted data. The program is functional in communication data mining since the tool allows researchers to search relevant Twitter communication streams using a contextualized search terms (Hansen et al. 2010). In our study, we utilized "LA Flood" to search and extract the 2016 Louisiana flood response communication data. 


\subsection{Measurement and methods}

This study involves two main concepts: (1) response communication, (2) cultural characteristics. First, 2016 Louisiana flood response communication was operationalized as collective interactions among people who are imparting and exchanging information about Louisiana flood via social media. The concept was measured by Twitter users' communication behaviors of information sharing on Twitter. The researchers conducted network analysis to identify the whole communication network structure, and cluster analysis to identify sub-group structures. While conducting a network analysis, network nodes were identified. Nodes indicate Twitter users, entities of the communication, who posted Tweets including "LA Flood" during the observation period, and additional Twitter users who respond to those labeled Tweets (Smith et al. 2009; Smith 2015). Then, edges (or links) among all users were identified based on their communication behaviors using Tween functions (1) mentioning one another's initial Tweets containing the "LA flood" and (2) directly replying to those initial Tweets. In addition, the direction of the communication among actors was coded. Lastly, the researchers identified the collective interactions and communication structure among all users by connecting actors through their edges with others.

After the communication structure was identified, the researchers conducted a cluster analysis using Clauset-Newman-Moore cluster algorithm. ${ }^{1}$ The cluster analysis assessed group structures (or clusters, communities) that have more connections with one another than expected in a random null model. The pattern of cluster connections provides insightful information about understanding the communication structure. In addition, the cluster analysis results support identification of similarities among actors within a cluster, and differences among actors across clusters.

Secondly, cultural characteristics were measured based on qualitative content analysis of attributes of Twitter users and the keywords shared within and across diverse clusters of users (Cho et al. 2012; Jung and Valero 2016). Given the large numbers of Twitter users involved in observed communication network, the study focused on identifying the cultures of key actors who led either a cluster or the entire communication structures. Key actors of both entire communication structures were identified based on the results of key actor analysis (based on betweenness centrality) of the communication network and its groups (Jung et al. 2014). Betweenness centrality was calculated based on following equation below.

$$
g(v)=\sum_{s \neq v \neq t} \frac{\sigma_{s t}(v)}{\sigma_{s t}}
$$

Actors (Vertices) with high betweenness may have considerable influence within a network by virtue of their control over information passing between others. They are also the ones whose removal from the network will most disrupt communications between other vertices because they lie on the largest number of paths taken by messages.

Then, the researchers sought specific categories as the indicators of user attributes. The categories include major funding sources of the users (e.g., public, nonprofit, private),

1 "Clauset-Newman-Moore cluster algorithm is one of the most cited methods in the literature which focuses on dealing with large networks" (Vieira et al. 2014, p. 2). 
jurisdictional responsibility (e.g., federal, state, county, city), and types of industries (e.g., faith based, emergency management, performing art). Next, keyword analysis was conducted to identify the most frequently mentioned and shared 'words' within the key groups. The results of the key word analysis not only identified both common/distinctive cultural characteristics of within cluster communications, but also supported the cultural characteristics identified based on user attributes.

\section{Results and findings}

\subsection{RQ1: response communication structure}

\subsubsection{Overarching communication network}

During the observation period, 3206 authentic Twitter users exchanged ideas and shared response information with each other. Users communicated with each other a total of 9282 times by mentioning or replying to initial Tweets about the 2016 Louisiana Flood. Of which, 5878 of them were unique interactions without any duplicating or self-referring Tweets. The communication network is a loosely connected system with density ${ }^{2}$ of $0.07 \%$. Yet, the average distance of a user from all other users is relatively close. In the observed response communication structure, a user can reach all other 3205 users, passing through only three and a half Tweets. The low density and low reciprocity with short distance indicate that the efficiency of observed communication network among Twitter users in information sharing or dissemination across users. Table 1 provides descriptive statistics of the 2016 Louisiana Flood response communication network.

The communication network consists of 102 clusters (also called divisions, groups or communities) of Twitter users. The modularity, $51 \%$, in Table 1 indicates greater internal connections (intra-group communication) and lower external connections (inter-group communication). Figure 1, below, visualizes entire communication network as well as inter/intra-cluster-connections among the twitter users.

Figure 1 and Table 2 indicate that the communication network has the scale-free property: numerous small groups coexist with huge groups with exceptionally large number of Twitter users. $77.69 \%$ of users $(\mathrm{N}=2491)$ belongs to $5 \%$ of groups $(\mathrm{N}=5)$ in this communication network. In addition, $84.47 \%(\mathrm{~N}=4965)$ interaction edges on the communication network point to the $5 \%$ of groups.

\subsubsection{Communication across major clusters}

In the observed communication network, clusters 2 and 3 lead the inter-group communications among the top five clusters. Clusters 2 and 3 frequently interact with one another as well as with all other clusters, while other clusters either receive or send information to each other. In particular, cluster 1 has less out-going ties to other groups, but many incoming ties from clusters 2 and 3. Yet group 1 has no input from groups 4 and 5. Group 2 has comparatively many out-going ties to groups 1,3 and 4, and receives a strong input from group 2. Group 2 receives ties all other major groups. Group 3 has both strong outgoing and in-coming ties from group 2. Group 3 also receives ties from all other major

${ }^{2}$ Density is defined as the number of observed connections among nodes, divided by the total possible connections nodes could have (Scott 2012). 
Table 1 Descriptive statistics of the response communication network
Graph metrics

\begin{tabular}{ll}
\hline Node (twitter users) & 3206 \\
Edges (directed communication) & 9282 (total edges) \\
& 5878 (unique edges) \\
& 3040 (duplicates) \\
Density & 470 (self-loops) \\
Distance (avg.) & 0.0007 \\
Groups (modularity) & 3.4324 \\
\end{tabular}

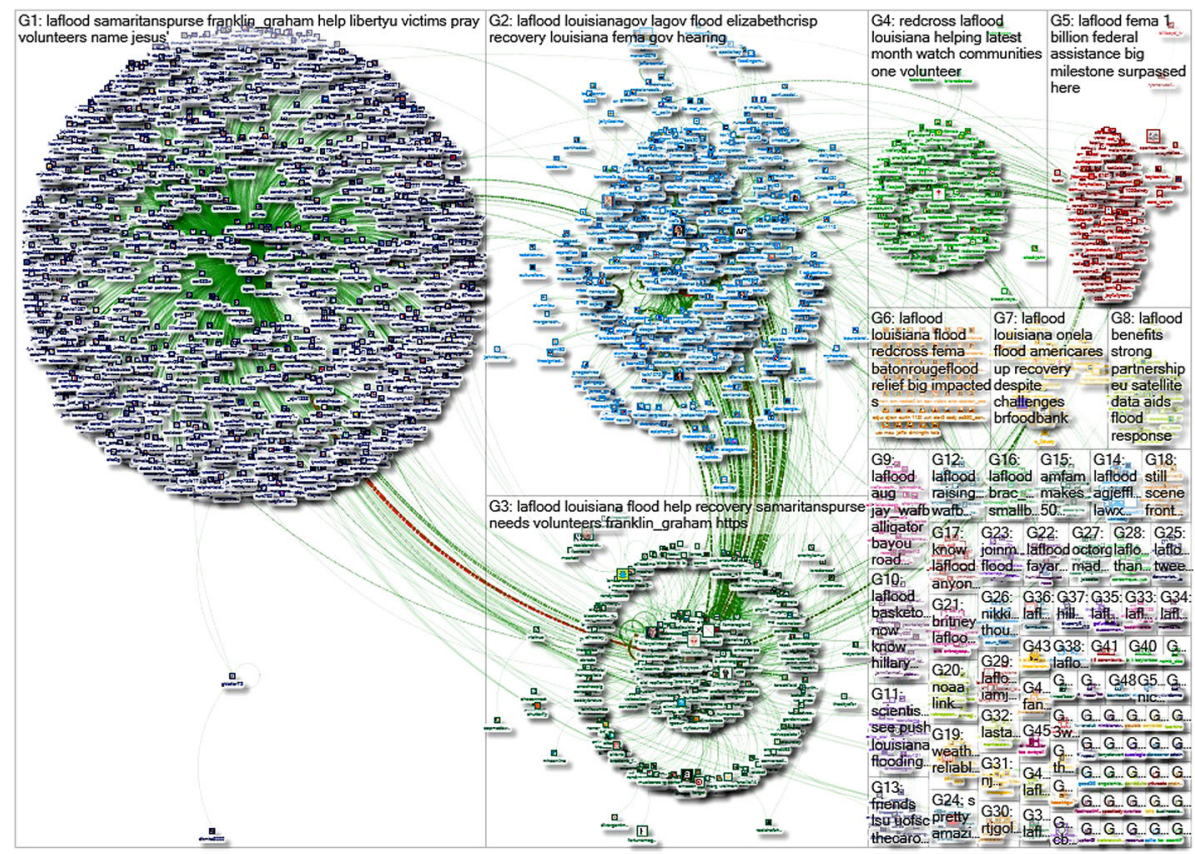

Fig. 1 Response communication network

groups. Group 4 and 5 have mutual ties with group 2 and 3, but they only receive ties from group 1. This inter-group communication structure indicates that groups 2 and 3 bridge communication across the major clusters through their mutual group communication, as well as each of their connections with all other groups. In particular, groups 2 and 3 bridge communication among groups 1, 4, and 5. Figure 2 summarizes information of inter-group communication among the top five groups.

\subsection{RQ2: emerging cultural indicators of emergency response communications?}

The analysis of key words and actor attributes of major groups indicates strong cultural homophily, or birds of feather tendency. Twitter users using similar culturally biding key words tend to belong to the same group. In other words, groups sharing cultural identifies 
Table 2 Response communication groups

\begin{tabular}{lcclll}
\hline Group rank & \multicolumn{2}{l}{ Users } & & \multicolumn{2}{l}{ Interactions } \\
\cline { 2 - 3 } \cline { 5 - 6 } \cline { 5 - 6 } & $\mathrm{N}(\%)$ & Cum $\%$ & & $\mathrm{~N}(\%)$ & Cum $\%$ \\
\hline 1 & $1211(37.77)$ & 37.77 & & $2797(47.58 \%)$ & 47.58 \\
2 & $571(17.81)$ & 55.58 & & $1257(21.38 \%)$ & 68.69 \\
3 & $414(12.91)$ & 68.49 & & $613(10.43 \%)$ & 79.39 \\
4 & $163(5.08)$ & 73.57 & & $154(2.62 \%)$ & 82.01 \\
5 & $132(4.12)$ & 77.69 & & $144(2.45 \%)$ & 84.46 \\
6 & $53(1.65)$ & 79.34 & & $46(0.78 \%)$ & 85.24 \\
7 & $51(1.59)$ & 80.93 & & $85(1.45 \%)$ & 86.69 \\
8 & $36(1.12)$ & 82.05 & & $36(0.61 \%)$ & 87.30 \\
9 & $22(0.69)$ & 82.74 & & $19(0.32 \%)$ & 87.62 \\
10 & $21(0.66)$ & 83.4 & & $20(0.34 \%)$ & 87.96 \\
\hline
\end{tabular}

Group 2

Sending: 150

Receiving: 349

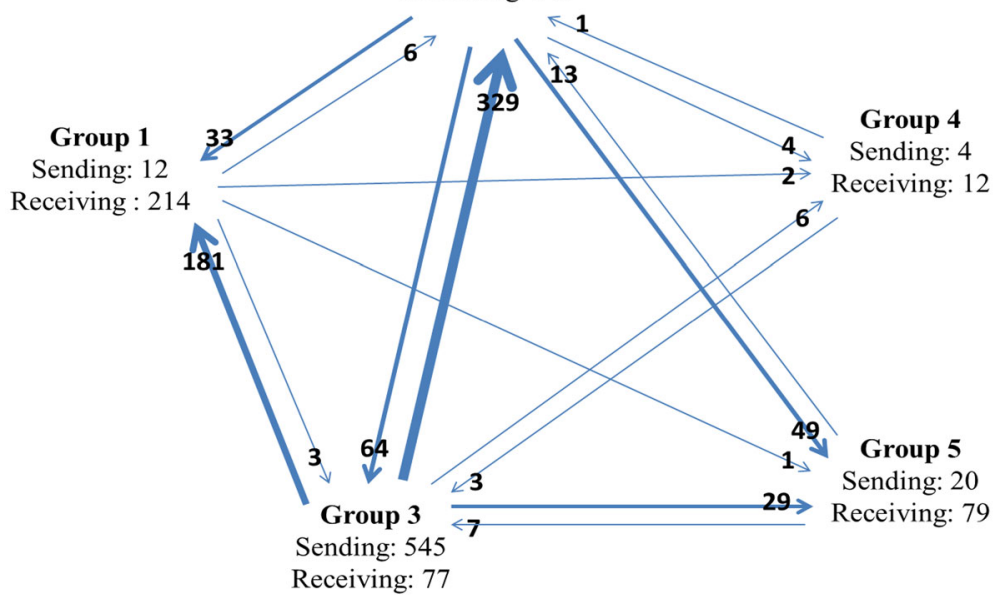

Fig. 2 Inter-group communication among top five groups

tend to communicate one another more frequently. Table 3 provides the summary of keyword and key actor analysis.

\subsubsection{Common culture of within-cluster-communications}

The group 1 can be characterized as faith-based communication cluster. The key words used by Group 1 members were "Samaritan's Purse (faith-based relief nonprofit)," "Franklin Graham (CEO of evangelic/Christian association)" "Liberty University (the largest Christian university Southern Baptist affiliation), "Pray," and "Jesus Name" indicates a strong sentiment of Christianity. In addition, the users in the group tend to share those key words by mentioning or replying to the tweets made by "Franklin Graham (R)," "Samaritan's Purse (M)," and "Liberty University (M)." This is associated with the 
Table 3 Key words and key actors

\begin{tabular}{|c|c|c|}
\hline Rank & Key word (count) & To whom \\
\hline \multicolumn{3}{|c|}{ Group 1 (the largest cluster) } \\
\hline 1 & Samaritanspurse (1574) & Franklin Graham (R) \\
\hline 2 & Franklin_graham (1565) & Samaritans' Purse (M) \\
\hline 3 & Help (1008) & Liberty University (M) \\
\hline 4 & Liberty University (816) & \\
\hline 5 & Victims (809) & \\
\hline 6 & Pray (576) & \\
\hline 7 & Volunteers (558) & \\
\hline 8 & JESUS name (558) & \\
\hline \multicolumn{3}{|c|}{ Group 2 (2nd largest cluster) } \\
\hline 1 & Louisianagov (694) & LA Gov Office (R) \\
\hline 2 & Elizabethcrisp (207) & Gannett's LA \& MS papers (R) \\
\hline 3 & Recovery (195) & Elizabethcrisp (M) \\
\hline 4 & Fema (139) & Barack Obama (M) \\
\hline 5 & Gov hearing (136) & \\
\hline \multicolumn{3}{|c|}{ Group 3 (3rd largest cluster) } \\
\hline 1 & Help (120) & Hillary Clinton (R) \\
\hline 2 & Recovery (82) & Moskov (R) \\
\hline 3 & Samaritanspurse (74) & Samaritans' Purse (M) \\
\hline \multirow[t]{3}{*}{4} & Needs volunteers (72) & FEMA region $6(\mathrm{M})$ \\
\hline & & AmeriCorps (M) \\
\hline & & LA Gov Office (R) \\
\hline \multicolumn{3}{|c|}{ Group 4 (4th largest cluster) } \\
\hline 1 & Redcross (345) & Red Cross (M) \\
\hline 2 & Helping (95) & RC, Baton Rouge, LA (M) \\
\hline 3 & Latest month (94) & Red Cross LA (M) \\
\hline 4 & Watch communities (93) & \\
\hline 5 & Volunteer (81) & \\
\hline \multicolumn{3}{|c|}{ Group 5 (5th largest cluster) } \\
\hline 1 & Fema (126) & FEMA (R \& M) \\
\hline 2 & 1 Billion (114) & FEMA region $6(\mathrm{M})$ \\
\hline 3 & Federal assistance (110) & \\
\hline 4 & Big milestone surpassed (108) & \\
\hline
\end{tabular}

predominant local culture, strong involvement and power of faith-based organizations in the regional/community affairs.

The group 2's communication pattern shows common attitude towards local and/or public authority. Users in this group form their communication network by mentioning or responding to tweets made by "LA governors' office(R)," "Gannett's Louisiana and Mississippi papers [regional news] (R)," "Elizabeth Crisp [Louisiana capitol reporter] (M)," and "Barack Obama [U.S. President] (M)." In addition, the key words shared across 
the group members, such as "LA government" "Elizabeth Crisp [Louisiana capitol reporter]," "FEMA," and "Government Hearing" may indicate the people's efforts to remind local and/or public authorities' responsibility for emergency response. Or it could be the local authorities' efforts to establish public exposure and to overcome the locals' deep-rooted distrust again them. In either way, the deep-rooted distrust against the local authorities provide some clues to this emergency response communication behavior.

Group 3 communication is organized based on action-focused, multi culture. There was no common/dominant attribute shared across individual group members. Rather the group has a little bit of every culture. Group members exchange Tweets from diverse sources, including "Hillary Clinton [Politician, Presidential Candidate] (R)," "Moskov [Humanitarian Venture] (R)," Samaritans' Purse [faith-based relief nonprofit] (M)," FEMA region 6 [Federal Emergency Agency Regional Branch] (M)," "AmeriCorp [Civil Service Funding Organization] (M)," and "LA Governor's Office (R)." Yet, key words shared among diverse group members were very action based, such as "Help," "Recovery," and "Need volunteers." The keywords explain that the group's sole focus is on recovery and response operation, the ultimate goal of overall actors in this communication.

The communication among members of group 4 can be characterized as a humanitarian nonprofit emergency response network across jurisdictions. Twitter users shared information Tweeted by "American Red Cross [National] (M)," "Red Cross, Baton Rouge [Affected Region] (M)," and "Red Cross Louisiana (M)." In addition, keywords shared by those Tweets were "helping," "latest month," "Watch community," and "Volunteers." The key words indicate information about how the humanitarian nonprofits have worked in the affected community from the beginning of the flood in the region. This observation confirms that after Hurricane Katrina and Rita in 2005, nonprofits became one of the active and well-trusted actors during disaster response in LA.

Lastly, group 5 is the Federal Emergency Management Agency (FEMA) communication network. Group members exchanged information about federal assistance from both FEMA's headquarters and regional office. During the communication, information about FEMA operations were shared through keywords including "FEMA," "1 billion [Federal assistance]," and "big milestone surpassed [self-evaluation]."

\subsubsection{Communication culture across the clusters}

The analysis results reveal that culture may be the indicators of intergroup communication as well. Groups sharing cultural attributes tend to have more frequent interactions while groups of distinctive cultures tend not to communicate. However, the system is not segregated since groups incorporating multi-cultures have bridged communication gaps among groups with distinctive cultures. In particular, groups 3, based on its cultural diversity, are able to communicate with all other cultural groups. Some local government members of the group 3 communicated with group 2 and delivered formal information to the group 1 (faith-based response). In addition, the public authorities embedded in the group 2 enabled its interactions with the groups 4 (red-cross) and 5 (FEMA). In addition, the group 2 delivered information to group 3, which was connected to the group 1 .

\subsection{RQ3: cultural drivers of 2016 Louisiana flood response communications}

Cultural drivers of the response community are identified based on analysis of common attributes of 10 influencers. The drivers were religion, local authority, and humanitarian nonprofits. The results reflect the major Louisiana local cultures. Strong association of 
religion with local people and community's daily life, continuous efforts to overcome deep-rooted distrust to local authorities, and emerging humanitarian nonprofit in disaster response were outstanding during Hurricane Katrina as well (Fig. 3).

\section{Conclusion}

The purpose of this study was to fill a gap in the literature about the general nuance of culture in social media communication during disaster response operations. Results highlight that 2017 Louisiana Flood response communication showed strong cultural characteristics. Among all the cultures in Louisiana, faith-based, distrust of local authority, and humanitarian assistance were prominent cultural indicators in the flood response communication. In particular, each communication group was composed of actors sharing common cultural background and speaking similar languages (key words). In addition, inter-group communications emerge when communication group have some common cultural agenda. In other words, groups sharing some key words tend to communicate more frequently than those which do not. Thus, intergroup communications were bridged by the groups carrying multiple cultural characteristics.

As a practical implication, timely using social media after an event occurs can help practitioners enhance emergency response communication networks, such as the 2011 Japan earthquake (Cho et al. 2012), the 2012 Gumi chemical spill in South Korea (Jung and Park 2016), and the Middle East Respiratory Syndrome (MERS) Coronavirus (Kim 2017). For instance, realtime data directly collected from social media overtime provides

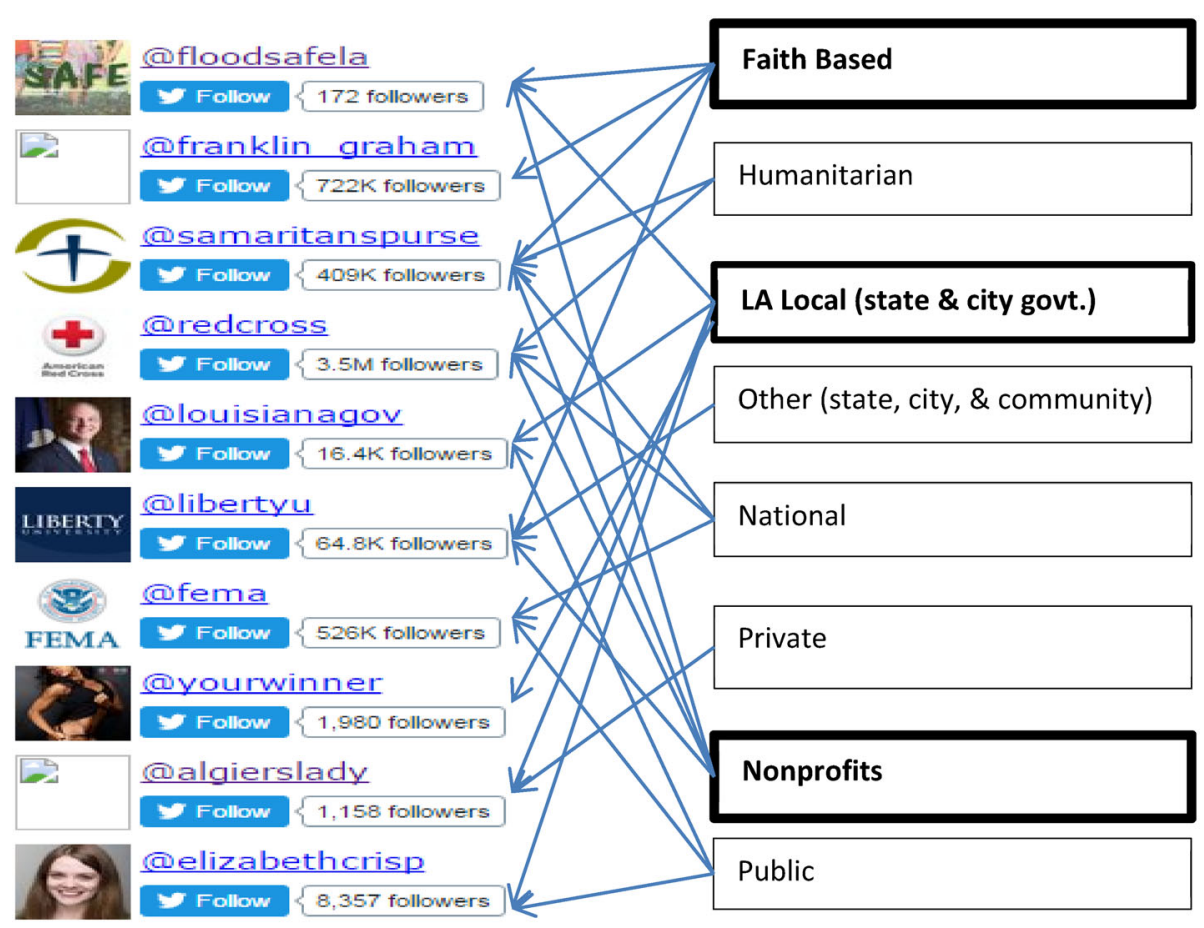

Fig. 3 Top 10 influencers and their cultural attributes 
first responders with an opportunity to assess whether cultures embedded in local community matter in facilitating communications with key stakeholders such as local governments and nonprofits via social media. Also, social network analysis with social media datasets can allow practitioners to identify the most influential stakeholders and keywords as needs of affected communities over time (Jung et al. 2017). The application of a webometric approach as a method of social network analysis with social media datasets will be critically considered as a smart big-board which exactly identify dominant cultures of key stakeholders' communications, which helps an organization respond to an unexpected event and develop communication strategies.As with any case study, there are limitations and recommendations for future research. First, researchers often criticize single-case study designs for lacking external validity because the study results are harder to generalize to larger populations. Sobeck (2003) and Yin (1994), among other scholars, make the argument that case study research is attempting to create analytic, and not statistical, generalizations. Future research should replicate the data collection and analysis methodology to study culture in other disasters, such as the recent 2016 disasters: Korean Earthquake, San Jose Flood, and Fort Lauderdale Airport Shooting. Second, researchers in this case study collected the Twitter data for dates following the disaster. Similar to the study on Twitter use before, during, and after Superstorm Sandy (Jacques and Knox 2016), a future study could expand the Twitter data collection to capture cultural communications throughout the disaster.

\section{References}

Adger, W.N., Barnett, J., Chapin Iii, F.S., Ellemor, H.: This must be the place: underrepresentation of identity and meaning in climate change decision-making. Glob. Environ. Polit. 11(2), 1-25 (2011)

Airriess, C.A., Li, W., Leong, K.J., Chen, A.C.C., Keith, V.M.: Church-based social capital, networks and geographical scale: Katrina evacuation, relocation, and recovery in a New Orleans Vietnamese American community. Geoforum 39(3), 1333-1346 (2008)

Ancelet, B.J., Gaudet, M., Lindahl, C.: Second Line Rescue: Improvised Response to Katrina and Rita. University Press of Mississippi, Jackson (2013)

Axelrod, R.: The dissemination of culture: a model with local convergence and global polarization. J. Confl. Resolut. 41, 203-226 (1997)

Bergeron, W.P.: Considering culture in evacuation planning and consequence management. J. Emerg. Manag. 13(2), 87-92 (2014)

Bifet, A., Holmes, G., Pfahringer, B., Gavalda, R.: Detecting sentiment change in twitter streaming data. In: WAPA, pp. 5-11 (2011)

Canton, L.G.: Is your planning culturally sensitive? Emergency managers need to develop cultural competence to better serve our communities. http://www.emergencymgmt.com/emergency-blogs/ managing-crisis/Is-Your-Planning-Culturally-Sensitive.html (2015)

Centola, D., Gonzalez-Avella, J.C., Eguiluz, V.M., San Miguel, M.: Homophily, cultural drift, and the coevolution of cultural groups. J. Confl. Resolut. 51(6), 905-929 (2007)

Chiglinsky, K.: Louisiana flood of 2016 seen costing up to \$15 billion, mostly uninsured. Bloomberg News. http://www.nola.com/weather/index.ssf/2016/09/louisiana_flood_of_2016_seen_c.html (2016)

Cho, S.E., Choi, M.G., Park, H.W.: Government-civic group conflicts and communication strategies: a text analysis of TV debates on Korea's import of U.S. beef. J. Contemp. East. Asia 11(1), 1-20 (2012)

Cohen, S., Eimicke, W., Horan, J.: Catastrophe and the public service: a case study of the government response to the destruction of the World Trade Center. Spec. Issue Public Adm. Rev. 62, 24-32 (2002)

Comfort, L.K., Ko, K., Zagorecki, A.: Coordination in rapidly evolving disaster response system: the role of information. Am. Behav. Sci. 48(3), 295-313 (2004)

Comfort, L.K., Waugh, W.L., Cigler, B.A.: Emergency management research and practice in public administration: emergency, evolution, expansion, and future directions. Public Adm. Rev. 72(4), 539-547 (2012) 
Comfort, L.K., Scheinert, S., Yeo, J., Schuh, R., Duran, L., Potter, M.A.: Using bayesian influence diagrams to assess organizational performance in 4 california county health departments, April-July 2009. J. Public Health Manag. Pract. 19, S63-S64 (2013)

Cross, T.L.: Towards a Culturally Competent System of Care: A Monograph on Effective Services for Minority Children who are Severely Emotionally Disturbed. Georgetown University Child Development Center, Washington (1989)

Decker, B.: Acadiana people: where will we grow next? The advertiser. http://www.theadvertiser.com/story/ news/local/acadiana/2014/06/07/acadian-people-will-grow-next/10182909/ (2014)

Domonoske, C.: Louisiana floods leave at least 6 dead, tens of thousands forced from homes. NPR. http:// www.npr.org/sections/thetwo-way/2016/08/15/490081973/louisiana-floods-leave-at-least-5-dead-tensof-thousands-forced-from-homes (2016)

Eikenberry, A.M., Arroyave, V., Cooper, T.: Administrative failure and the international NGO response to Hurricane Katrina. Public Adm. Rev. 67(s1), 160-170 (2007)

Falkheimer, J., Heide, M.: Multicultural crisis communication: towards a social constructionist perspective. J. Conting. Crisis Manag. 14(4), 180-189 (2006)

Gunn, B., Cook, L.L.: Thousands flooded, with more rain to come for Louisiana. The advocate. http://www. govtech.com/em/disaster/Thousands-flooded-with-more-rain-to-come-for-Acadiana.html (2016)

Harrald, J.R.: Emergency management restructured: intended and unintended outcomes of actions taken since 9/11. In: Rubin, C.B. (ed.) Emergency Management: The American Experience 1900-2010, 2nd edn, pp. 167-189. CRC Press, Boca Raton (2012)

Hansen, D., Shneiderman, B., Smith, M.A.: Analyzing Social Media Networks with NodeXL: Insights from a Connected World. Morgan Kaufmann, Burlington (2010)

Hofstede, G.: Cultural constraints in management theories. Acad. Manag. Exec. 7(1), 81-94 (1993)

House, R.J., Hanges, P.J., Javidan, M., Dorfman, P.W., Gupta, V.: Culture, Leadership, and Organizations: The GLOBE Study of 62 Societies. Sage Publications, Thousand Oaks (2004)

Hu, Q., Knox, C.C., Kapucu, N.: What have we learned since September 11, 2001? A network study of the Boston marathon bombings response. Public Adm. Rev. 74(6), 698-712 (2014)

Hughes, A.L., Palen, L.: The evolving role of the public information officer: an examination of social media in emergency management. J. Homel. Secur. Emerg. Manag. 9(1), 1-20 (2012)

Jacques, P., Knox, C.C.: Hurricanes and hegemony: a qualitative analysis of micro-level climate denial discourses. Environ. Polit. 25(5), 831-852 (2016)

Joyce, C.: Outdated FEMA flood maps don't account for climate change. NPR. http://www.npr.org/2016/09/ 15/492260099/outdated-fema-flood-maps-dont-account-for-climate-change (2016)

Jung, K., Chilton, K., Valero, J.N.: Uncovering stakeholders in public-private relations on social media: a case study of the 2015 Volkswagen scandal. Qual. Quant. 51(3), 1113-1131 (2017)

Jung, K., Park, H.W.: Tracing interorganizational information networks during emergency responses: a webometric approach to the 2012 Gumi chemical spill. Gov. Inf. Q. 33(1), 133-141 (2016)

Jung, K., Valero, J.N.: Assessing the evolutionary structure of homeless network: social media use, keywords, and influential stakeholders. Technol. Forecast. Soc. Chang. 110, 51-60 (2016)

Jung, K., No, W., Kim, J.W.: Who leads nonprofit advocacy through social media? Some evidence from the Australian marine conservation society's twitter networks. J. Contemp. East. Asia 13(1), 69-81 (2014)

Jurkiewicz, C.L.: Louisiana's ethical culture and its effect on the administrative failures following Katrina. Public Adm. Rev. 67(s1), 57-63 (2007)

Jurkiewicz, C.L.: Political leadership, cultural ethics and recovery: Louisiana Post-Katrina. Public Organ. Rev. 9(4), 353 (2009)

Kapucu, N.: Interagency communication networks during emergencies: boundary spanners in multiagency coordination. Am. Rev. Public Adm. 36(2), 207-225 (2006a)

Kapucu, N.: Public-nonprofit partnerships for collective action in dynamic contexts of emergencies. Public Adm. 84(1), 205-220 (2006b)

Kim, J.W., Kim, Y., Suran, M.: Emergency-response organization utilization of social media during a disaster: a case study of the 2013 Seoul floods. J. Contemp. East. Asia 14(2), 5-15 (2015)

Kim, K.: How did South Korean governments respond during 2015 MERS outbreak?: application of the adaptive governance framework. J. Contemp. East. Asia 16(1), 69-81 (2017)

Knoke, D.: Political Networks: The Structural Perspective. Cambridge University Press, New York (1990)

Knox, C.C.: Public administrators' use of social media platforms: overcoming the legitimacy dilemma? Adm. Soc. 48(4), 477-496 (2016)

Leong, K.J., Airriess, C.A., Li, W., Chen, A.C.C., Keith, V.M.: Resilient history and the rebuilding of a community: the Vietnamese American community in New Orleans East. J. Am. Hist. 94(3), 770-779 (2007) 
Lee, B.K.: Audience-oriented approach to crisis communication: a study of Hong Kong consumers' evaluation of an organizational crisis. Commun. Res. 31(5), 600-618 (2004)

Lui, B.F., Fraustino, J.D., Jin, Y.: How disaster information form, source, type, and prior disaster exposure affect public outcomes: jumping on the social media bandwagon? J. Appl. Commun. Res. 43(1), 44-65 (2015)

Louisiana Severe Storms and Flooding (DR-4277): Federal Emergency Management Agency. https://www. fema.gov/disaster/4277?utm_source=hp_promo\&utm_medium=web\&utm_campaign=femagov_hp (2016)

McPherson, J.M., Smith-Lovin, L., Cook, J.: Birds of a feather: homophily in social networks. Ann. Rev. Sociol. 27, 415-444 (2001)

Mileti, D.: Disasters by Design: A Reassessment of Natural Hazards in the United States. Joseph Henry Press, Washington (1999)

Mitchell, D.J.: Baton Rouge grew after Katrina while forging closer ties to recovering New Orleans. The advocate. http://www.theadvocate.com/baton_rouge/news/article_4871291f-0606-520b-a6b5df73c446c750.html (2015)

Neal, D.M., Phillips, B.D.: Effective emergency management: Reconsidering the bureaucratic approach. Disasters 19(4), 327-337 (1995)

O'Donoghue, J.: What should we make of John Bel Edwards high approval ratings? The Times-Picayune. http://www.nola.com/politics/index.ssf/2016/12/john_bel_edwards_approval_rati_1.html (2016)

Office of Minority Health (OMH): Cultural competency curriculum for disaster preparedness and crisis response. Department of Health and Human Sevices. https://cccdpcr.thinkculturalhealth.hhs.gov/ (2013)

Palttala, P., Boano, C., Lund, R., Vos, M.: Communication gaps in disaster management: perceptions by experts from governmental and non-governmental organizations. J. Conting. Crisis Manag. 20(1), 2-12 (2012)

Pennington-Gray, L., Kaplanidou, K., Schroeder, A.: Drivers of social media use among African Americans in the event of a crisis. Nat. Hazards 66(1), 77-95 (2013)

Pew Research Center: State governments viewed favorably as federal rating hits new low. http://www. people-press.org/2013/04/15/state-govermnents-viewed-favorably-as-federal-rating-hits-new-low/ (2013)

Pew Research Center: Public trust in government: 1958-2015. http://www.people-press.org/2015/11/23/ public-trust-in-government-1958-2015/ (2015)

Reynolds, B., Seeger, M.W.: Crisis and risk communication as an integrative model. J. Health Commun. 10(1), 43-55 (2005)

Renzaho, A.M., Oldroyd, J.C.: Closing the gap in maternal and child health: a qualitative study examining health needs of migrant mothers in Dandenong, Victoria, Australia. Matern. Child Health J. 18(6), 1391-1402 (2014)

Rosenthal, J., Masarech, M.A.: High-performance cultures: how values can drive business results. Glob. Bus. Organ. Excell. 22(2), 3-18 (2003)

Scott, J.: Social Network Analysis. Sage, Beverley Hills (2012)

Simms, C.D.: Canada's Fort McMurray fire: mitigating global risks. Lancet Glob. Health 4(8), e520 (2016)

Simon, T., Goldberg, A., Aharonson-Daniel, L., Leykin, D., Adini, B.: Twitter in the cross fire-the use of social media in the Westgate Mall terror attack in Kenya. PLoS ONE 9(8), e104136 (2014)

Smith, M.: Catalyzing social media scholarship with open tools and data. J. Contemp. East. Asia 14(2), 87-96. doi:10.17477/jcea.2015.14.2.087. http://eastasia.yu.ac.kr/documents/Smith_14_2.pdf (2015)

Smith, M.A., Shneiderman, B., Milic-Frayling, N., Mendes Rodrigues, E., Barash, V., Dunne, C., Gleave, E.: Analyzing (social media) networks with NodeXL. In: Proceedings of the Fourth International Conference on Communities and Technologies, pp. 255-264. ACM (2009)

Sobeck, J.: Comparing policy process frameworks: what do they tell us about group membership and participation for policy development? Adm. Soc. 35(3), 350-374 (2003)

Sylves, R.: Disaster Policy and Politics, pp. 46-75. CQ Press, a Division of Congressional Quarterly, Washington (2008)

Tinker, T., Vaughan, E.: Risk and crisis communications: best practices for government agencies and nonprofit organizations. https://www.boozallen.com/content/dam/boozallen/media/file/Risk-and-CrisisCommunications-Guide.PDF (2010)

Tinsley, C.H., Brett, J.M.: Managing workplace conflict in the United States and Hong Kong. Organ. Behav. Hum. Decis. Process. 85(2), 360-381 (2001)

Tovar, A., Renzaho, A.M., Guerrero, A.D., Mena, N., Ayala, G.X.: A systematic review of obesity prevention intervention studies among immigrant populations in the US. Curr. Obes. Rep. 3(2), 206-222 (2014) 
van der Wiel, K., Kapnick, S.B., van Oldenborgh, G.J., Whan, K., Philip, S., Vecchi, G.A., Singh, R.K., Arrighi, J., Cullen, H.: Rapid attribution of the August 2016 flood-inducing extreme precipitation in south Louisiana to climate change. Hydrol. Earth Syst. Sci. Discuss. 2016, 1-40 (2016)

Vieira, V.D.F., Xavier, C.R., Ebecken, N.F.F., Evsukoff, A.G.: Performance evaluation of modularity based community detection algorithms in large scale networks. Math. Probl. Eng. 2014, 502809 (2014). doi: $10.1155 / 2014 / 502809$

Wang, S.Y.S., Zhao, L., Gillies, R.R.: Synoptic and quantitative attributions of the extreme precipitation leading to the August 2016 Louisiana flood. Geophys. Res. Lett. 43(22), 11805-11814 (2016)

Waugh Jr., W.L., Streib, G.: Collaboration and leadership for effective emergency management. Spec. Issue Public Adm. Rev. 66, 131-140 (2006)

Weare, C., Lichterman, P., Esparza, N.: Collaboration and culture: organizational culture and the dynamics of collaborative policy networks. Policy Stud. J. 42(4), 590-619 (2014)

Weng, L., Ratkiewicz, J., Perra, N., Gonçalves, B., Castillo, C., Bonchi, F., Flammini, A.: The role of information diffusion in the evolution of social networks. In: Proceedings of the 19th ACM SIGKDD International Conference on Knowledge Discovery and Data Mining, pp. 356-364. ACM (2013)

Xiao, Z., Tsui, A.S.: When brokers may not work: the cultural contingency of social capital in Chinese hightech firms. Adm. Sci. Q. 52(1), 1-31 (2007)

Yates, D., Paquette, S.: Emergency knowledge management and social media technologies: a case study of the 2010 Haitian earthquake. Int. J. Inf. Manag. 31(1), 6-13 (2011)

Yeo, J., Comfort, L.K.: An expected event, but unprecedented damage: structure and gaps of large-scale response coordination of the 2011 Thailand floods. Disaster Prev. Manag: An Int. J. 26(4), 458-470 (2017)

Yin, R.: Case Study Research. Sage, Thousand Oaks (1994)

Zhu, L., Anagondahalli, D., Zhang, A.: Social media and culture in crisis communication: McDonald's and KFC crises management in China. Public Relat. Rev. (2017). doi:10.1016/j.pubrev.2017.03.006 